\title{
The many modes of citizen science
}

\author{
Dick Kasperowski \\ Department of Philosophy, Linguistics and Theory of Science, Gothenburg University, Sweden/ \\ dick.kasperowski@gu.se \\ Christopher Kullenberg \\ Department of Philosophy, Linguistics and Theory of Science, Gothenburg University, Sweden
}

Citizen science is currently heralded by proponents for science and policy in many ways. From a science policy perspective, citizen science is often brought forward as a remedy to 'alternative facts' and to general issues of trust in science and politics. In many cases citizen science has been promoted in sociotechnical imaginaries of creating the 'open society' by democratizing science, facilitating scientific literacy, often via digital technologies and networking (Holocher-Ertl and ZSI, 2013; Nascimento et al., 2014). Here, an imaginary from science policy has emerged, one wherein citizen science is meant to "enable citizens and citizen groups to participate in evidence-based policy and decision-making" (Lamy, 2017:19).

However, in contrast to such general accounts, this special issue seeks to unpack citizen science, and instead approach it not as one, but as several different modes of social epistemologies. These diverse modes also instantiate a wide range of imagined epistemic agents; 'the citizen', 'the volunteer,',the participant', 'the crowd','the activist', 'the community' et cetera - agents that in one way or another perform scientific research without being a professional scientist. The reasons are as manifold as the identities. Sometimes citizens react to environmental injustice by creating their own instruments and data. Sometimes volunteers join already defined basic science projects and follow their programmatic guidelines, instructions and protocols. The motivations can be quite diverse; from the love of nature and science, to fascination with stellar objects, playing a competitive science game or just passing time.

This special issue of Science and Technology Studies is concerned with the epistemological and ontological diversity of citizen science, and the sometimes contested attempts to define it, as an interesting and fruitful phenomenon to explore from vantage points or perspectives in STS. During the past two decades there has been an increasing interest in this phenomenon, and currently citizen science is being introduced as a way to change the very landscape and culture of science. Citizen science, as constructed as something new and innovative, is however possible to trace in scientific publications back to at least the 1960s, and the notion is sometimes extended onward to the beginning of the 20th century, even if the concept 'citizen science' has its roots in the late 1980s and early 1990s. Historically, however, as Strasser et al. point out in this special issue, it is impossible to conceive of citizen science without the emergence of professional scientists in the mid $19^{\text {th }}$ century. It is actually professional science that is 'the new thing', and the citizen scientists have been there all along in the shadows. The professionalisation of science has in many cases even made volunteer 
contributors invisible, since scientists have often mistrusted their abilities, and eclipsed them away from proper acknowledgement in publications (see for example Cooper et al., 2014). However, this was also the case in the dawn of modern science, with examples from Robert Boyle and Carl Linneaus relying on a distributed network of helpers that disappeared in history while the image of the great genius scientist was successively constructed and socially as well as ideologically reinforced (see Shapin and Shaffer, 2011).

In STS the notion of citizen science is often associated with Alan Irwin's 1995 book Citizen Science: A Study of People, Expertise and Sustainable Development. Here Irwin analyses forms for deliberative governance in terms of the possibilities of a scientific citizenship in which people affected by the consequences of science and technology demand a say in decision-making; from the vantage point of politicians and also scientists such exercises tend to be configured primarily as a practice of public engagement which is concerned with involving the public as stakeholders in policy issues with an eye to establish legitimacy for the science conducted and the science policy decisions made. Well known examples would be deliberations on fishing quotas, nuclear power or gene technology, controversial issues in which the experts and what is often referred to as 'lay people' have had conflicting interests, knowledges and access to information. We might say that Irwin's core problem is the contradiction between epistocracy and democracy, where experts in science and technology often have a privileged position that informs decision-making in a way that shortcuts democracy.

However, this contradiction as described by Irwin, and many other STS scholars, unfolds in quite different directions when citizens not only are affected by scientific expertise, but themselves are creating or co-creating scientific knowledge. This rapidly expanding practice is the focal point of this special issue, in which citizen science is analysed from many angles. In light of these developments, this special issue suggests how STS itself can re-consider what is meant by citizen science. There are at least two broad trends in the relationship between science and citizens that prompts further reflection and empirical case studies:
Firstly, in 1996 Rick Bonney (Bonney, 1996) coined the term 'citizen science' from a very different standpoint than Irwin. Based at the Cornell Lab of Ornithology he described the type of research that had relied on volunteer observations of wildlife, especially birds, for a long time, but had the potential to grow with the emergence of new information- and communication technologies. This type of citizen science is initiated by professional scientists, who define research questions and protocols for classification and collection of data, and then solicit volunteer contributors to assists researchers with predefined tasks, often with the aim of being able to scale up such operations to include thousands of citizen scientists who can help speed up data collection and classification. The idea of the citizen and citizenship is indeed very different in this type of research practice since much of the research process is already staged by experts. However, critical accounts that simply dismiss this practice as 'crowdsourcing' and even as clever ways of recruiting free labour, mostly overlook more nuanced results of empirical studies. For example, Kasperowski and Hillman (2018) have shown that volunteer participants in Galaxy Zoo invent new ways of detecting artefacts in telescope images of galaxies and Ponti et al. (2018) have studied how epistemic cultures and values will develop in quite different ways contingent on whether or not the citizen science projects involve or do not involve gamification. Moreover, several studies have shown that participation in projects on biological conservation is often motivated by concerns of preservation and environmental issues and also involve learning (Jordan et al., 2011, n.d.; Liberatore et al., 2018).

Secondly, and perhaps more intuitively related to scientific citizenship, forms of citizen science exist that grow out of community initiatives in the collection and use of data in legal or political battles, frequently triggered by an environmental risk or health related issues. However, in contrast to Irwin's discussion on science shops and social experiments these community initiatives are created by non-professional scientists that formulate the scope and design of the entire research process in opposition to established scientific knowledge. Examples would include 
a diverse line of initiatives, from the Louisiana Bucket Brigades (Ottinger, 2010) fighting against the petrochemical industry, German/European Luftdaten.info that measures particulate matter in the air of polluted cities and Safecast, a project for mapping radioactivity downfall after the Fukushima disaster, only to name a few. Such initiatives rely heavily on scientific standards and technologies for validating data as a means of forming resistance against environmental inequalities (Kullenberg, 2015). Since the results of their investigations are often heavily scrutinized and criticized, perhaps in some cases even more so than the peer review practice of institutionalized science, they often employ innovative open science methods and practices. The drivers of this type of citizen science 'in the wild' do not always call themselves advocates of 'citizen science', but prefer terms such as 'civic science'. They wish to highlight that their practices embody an ethos of bottom-up expertise created by concerned people that are not sufficiently represented by current expert systems (see for example Public Lab, https://publiclab.org/about).

The rationale for this special issue is to explore how these forms of practice are transgressed or may even stand in mutual opposition to each other. The five contributions address both what citizen science is, and how it can be studied, as such they are all more or less concerned with attempting to define, delimit or extend the concept of citizen science, even making room for abandoning the concept altogether and replacing it with more contextually aware framings and conceptualizations. No matter where the reader arrives after thinking together with the authors of these articles, we hope that the contributions will spur further discussion and studies within STS communities. With the contemporary wish from science, policy and society for a more open and inclusive science, this will be a key question for scholars in the field.

The first paper in this special issue is by Sascha Dickel, Christoph Schneider, Carolin Thiem and Klara-Aylin Wenten, who focus on civic technoscience and point to the need of distinguishing it in contradistinction to citizen science and clarifying the differences and respective implications involved. While the latter is concerned with explaining the world, the accent in the former is more on constructing viable technological worlds. The different forms or approaches of civic technoscience; emancipatory, entrepreneurial and communicative, are shown to stage the actors in different ways compared to the often-heard rhetorical narratives associated with such initiatives. The authors clarify the processes of inclusion and exclusion in these 'ideal types' as heterogenous publics are assembled as 'performing audiences' in the technological worlds of civic technoscience.

The opportunities for citizen science, particularly the possibilities of community driven citizen science supportive of progress in environmental protection beyond the research phase is the subject of the discussion paper by Shannon Dosemagen and Alison Parker. They illustrate such possibilities along a spectrum of engagements with environmental issues as both US institutions and agencies move toward more inclusive visions of their tasks in tandem with a growth in community science where questions and methods are developed by local concerned groups. They propose a spectrum 'model' of engagement encompassing community initiatives, including education, research, management and regulatory decisions to enforce particular measures; all of this is exemplified by case studies for each category of activities concerned.

In her article on "Modes of Existences in Citizen Science: Thoughts from Earthquake Country" Charlotte Mazel-Cabasse explores the many existences of the risk of earthquakes to inform and complicate the discussion of what citizen science can and cannot be. Discussion pertains to three - of possibly even more - modes of existence of earthquake phenomena: (1) observation, collection of data and translation of mechanisms (of an earthquake), (2) visualization and quantification of the same and (3) personal and affective dimensions of the phenomenon. These modes of existence are all held to incorporate performative capacities. No mode of existence only describes an external reality, but rather in every instance it also works upon, transforms and modifies this reality. Opening up for such ontological issues prompts the question of what citizen science is and could be. A question is: which modes of existence are 
rendered invisible in the performative acts of inviting the 'outsider' - subjectivity, non-rationality - in the mode of existence that actualises a phenomenon as "scientific"? Mazel-Cabasse shows that subjectivity and non-rationality is never absent in any of the many modes of existence realizing an earthquake. This finding could be extended to the constitutive dimension of all objects of citizen science, for example, galaxies, birds, invasive species, air quality and more. The "quantification by means of instruments" currently appears to be the preferred mode of reducing phenomena to a mode of existence that sits well with citizen science.

The article "'"Citizen Science"? Rethinking Science and Public Participation" by Bruno J. Strasser, Jérôme Baudry, Dana Mahr, Gabriela Sanchez and Elise Tancoigne takes a broad view of what citizen science can be, ranging from epistemology to policy, to its social composition, as well as many different imaginaries of participation and democracy. They suggest that citizen science can be broken down to five distinct 'epistemic practices'. The epistemic practices identified that are able to better capture the diversity of citizen science projects are the following; 'sensing', 'computing', 'analysing', 'self-reporting' and 'making'. Such ideal types of epistemic practice, the authors argue, are more inclusive than simply using the notion of 'citizen science'. This is because they also incorporate other forms of scientific practice that are vital for understanding the many new forms of public participation in the production of scientific knowledge, practices that are easily overlooked when citizen science gains traction and greater popularity. Drawing on a historical overview of the emergence of the 'participatory' turn in the sciences, the authors critically discuss the political possibilities as well as limitations inherent in the way citizen science is being framed today.

The plethora of definitions and classifications of citizen science is also taken up by Phillip Schrögel and Alma Kolleck in their paper "The many faces of participation in science: Literature review and proposal for a three dimensional framework". Starting out by recognizing the traceability of the many participatory formats construed under the banner 'citizen science' to some broad common denominator, they identify two 'main paradigms', viz., dialogues about science and doing science, respectively. They also argue that the academic discussion on citizen science is highly normative as it proceeds around the quality of data or process. As such their ambition is to provide a descriptive model, based on a literature review of conceptual frameworks and typologies in science governance and in participatory research approaches. This is done in order to modify Archon Fungs's model for participatory democracy to accommodate the epistemic and normative focus with the reach of participatory projects beyond institutionalized science. In this they aim to overcome the divides constructed as participatory science governance and citizen science that are confined to "the silos of their respective academic tradition". Their proposal is a three-dimensional model, contrasting it to the usual one-dimensional (normative) linear scales of hierarchy; thence they argue for participation in all aspects of the scientific process. The proposed model actually provides some tentative answers to the question posed by Cabasse-Mazel regarding how citizen science can be constructed by adjoining different agents and their activities. However, as the authors clearly state the model cannot cover what Cabasse-Mazel call the personal affective dimensions; however it will provide material for discussions on the normative statements so often heard in a current discourse of "pushing all participatory approaches to [...] maximum openness."

Taken together, the five contributions on the epistemological and ontological diversity of citizen science all provide much needed perspectives for informed STS studies on the topic, both critical approaches as well as good arguments for engaging with these practices, Ultimately this might even lead to STS initiatives using citizen science as a potential powerful method for intervention. Thus, a new reflective theme can be introduced into STS, one which intervenes on an epistemological level in addition to the social level, hence accenting citizen science as a new social epistemology. What happens when STS engages with data collection and classification for epistemic justice, challenging established scientific knowledge? What does it mean to 'innovate methodologically' in order to perform 'engaged 
STS' to change actual scientific practices (see Wylie et al., 2017)? Such enterprises definitely challenge STS to move beyond its ambitions to critically approaching the social and cultural composition of science and technology, and go further by now also creating 'politically relevant' (in search for a better term) scientific knowledge. Here, citizen scientists have shown that local problems, made invisible either by aggregated established data or simply ignored by institutional science, can be addressed by members of the concerned communities themselves, using innovative scientific methods. What can STS offer in such movements? This is a question we encourage the reader of this special issue to hold on to while reading the contributions. 


\section{References}

Bonney R (1996) Citizen science: A Lab Tradition. Living Bird 15:7-15.

Cooper CB, Shirk J and Zuckerberg B (2014) The Invisible Prevalence of Citizen Science in Global Research: Migratory Birds and Climate Change. PLOS ONE 9(9): e106508. DOI: 10.1371/journal.pone.0106508.

Holocher-ErtI T and ZSI BK (2013) Deliverable no. D5. 3 Deliverable name Draft White Paper (Green Paper) Dissemination level PU WP no. 5 WP name Evaluation and policy recommendations. Available at: http:// www.socientize.eu/sites/default/files/SOCIENTIZE_D5.3.pdf (accessed 4 September 2015).

Irwin A (1995) Citizen Science: A Study of People, Expertise and Sustainable Development. Citizen Science: A Study of People, Expertise and Sustainable Development. London and New York: Routledge.

Jordan R, Gray S, Sorensen A, et al. (n.d.) Studying citizen science through adaptive management and learning feedbacks as mechanisms for improving conservation. Conservation Biology 30(3): 487-495. DOI: 10.1111/cobi.12659.

Jordan RC, Gray SA, Howe DV, et al. (2011) Knowledge Gain and Behavioral Change in Citizen-Science Programs. CONSERVATION BIOLOGY 25(6): 1148-1154. DOI: 10.1111/j.1523-1739.2011.01745.x.

Kasperowski D and Hillman T (2018) The epistemic culture in an online citizen science project: Programs, antiprograms and epistemic subjects. Social Studies of Science: 0306312718778806 . DOI: 10.1177/0306312718778806.

Kullenberg C (2015) Citizen Science as Resistance: Crossing the Boundary Between Reference and Representation. Available at: http://resistance-journal.org (accessed 30 August 2018).

Lamy $\mathrm{P}$ (2017) $L A B$ - FAB - APP — Investing in the European future we want. Luxembourg: Publications Office of the European Union, 2017: European Commission. Available at: http://ec.europa.eu/research/evaluations/ pdf/archive/other_reports_studies_and_documents/hlg_2017_report.pdf\#view=fit\&pagemode=none (accessed 21 June 2018).

Liberatore A, Bowkett E, MacLeod CJ et al. (2018) Social Media as a Platform for a Citizen Science Community of Practice. Citizen Science: Theory and Practice 3(1). DOI: 10.5334/cstp.108.

Nascimento S, Pereira ÂG and Ghezzi A (2014) From Citizen Science to Do It Yourself Science. Available at: http://www.researchgate.net/profile/Angela_Guimaraes_Pereira/publication/271834945_From_citizen_ science_to_do_it_yourself_science/links/54d34dd10cf250179181e7e2.pdf (accessed 22 March 2015).

Ottinger G (2010) Buckets of Resistance: Standards and the Effectiveness of Citizen Science. Science, Technology \& Human Values 35(2): 244-270. DOI: 10.1177/0162243909337121.

Ponti M, Hillman T, Kullenberg C, et al. (2018) Getting it Right or Being Top Rank: Games in Citizen Science. Citizen Science: Theory and Practice 3(1). DOI: 10.5334/cstp.101.

Shapin S and Schaffer S (2011) Leviathan and the Air-Pump: Hobbes, Boyle, and the Experimental Life. Princeton, NJ: Princeton University Press.

Wylie S, Shapiro N and Liboiron M (2017) Making and Doing Politics Through Grassroots Scientific Research on the Energy and Petrochemical Industries. Engaging Science, Technology, and Society 3(0):393-425. DOI: 10.17351/ests2017.134. 